Supporting Information

\title{
Synthesis and Characterization of CIT-13, a Germanosilicate Molecular Sieve with Extra-large Pore Openings
}

Jong Hun Kang, ${ }^{\S}$ Dan Xie, ${ }^{\dagger}$ Stacey I. Zones, ${ }^{\dagger}$ Stef Smeets, ${ }^{\ddagger}$ Lynne B. McCusker ${ }^{\ddagger \#}$, Mark E. Davis, ${ }^{{ }^{*} *}$

${ }^{\S}$ Chemical Engineering, California Institute of Technology, Pasadena, CA 91125

${ }^{\dagger}$ Chevron Energy Technology Co., 100 Chevron Way, Richmond, CA 94802

${ }^{\ddagger}$ Department of Materials and Environmental Chemistry, University of Stockholm, Svante Arrhenius väg 16C, SE-106 91 Stockholm, Sweden

\#Department of Materials, ETH Zurich, CH-8093, Zurich, Switzerland 


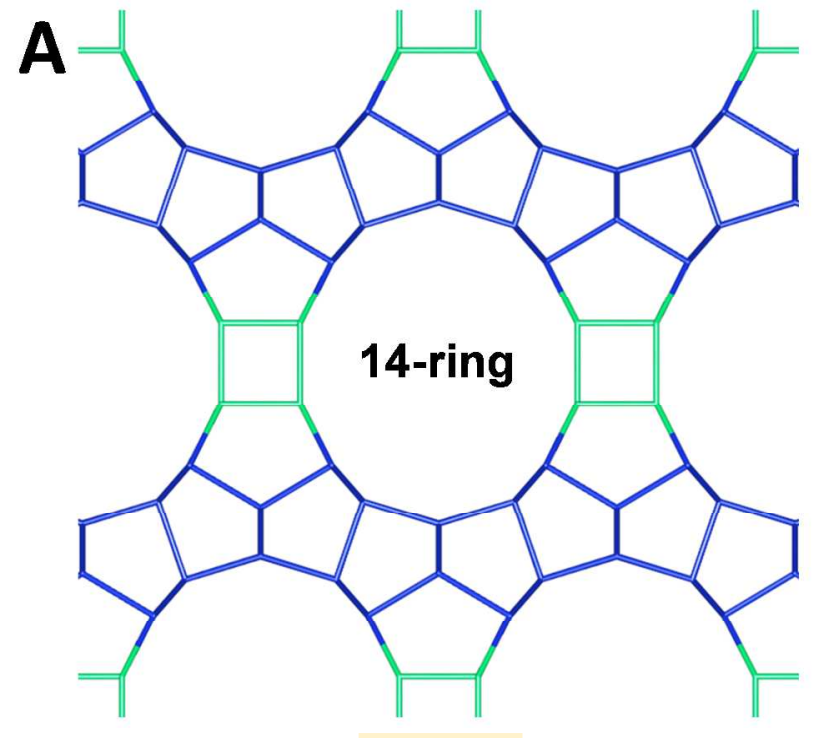

CIT-13

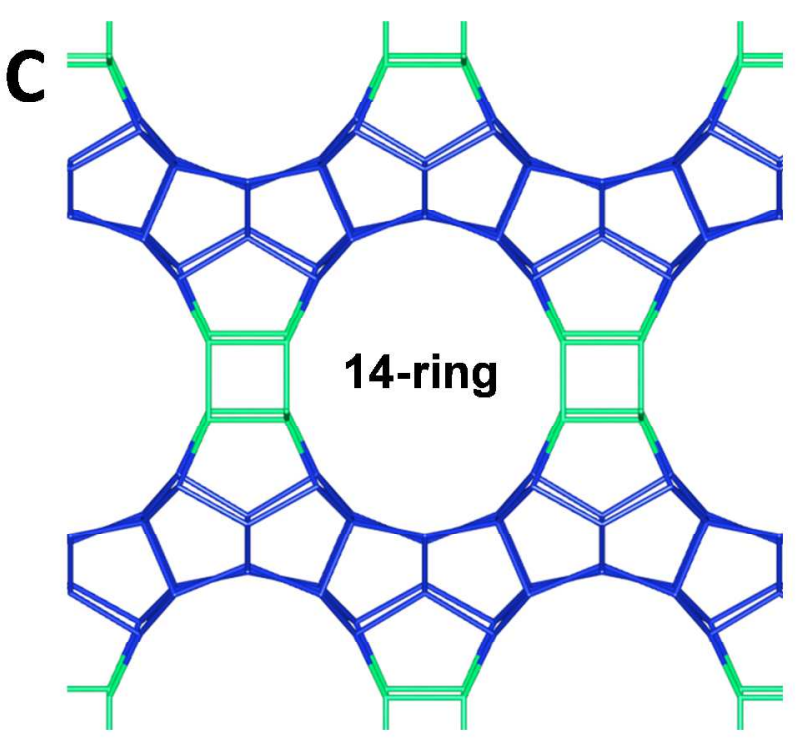

IM-12

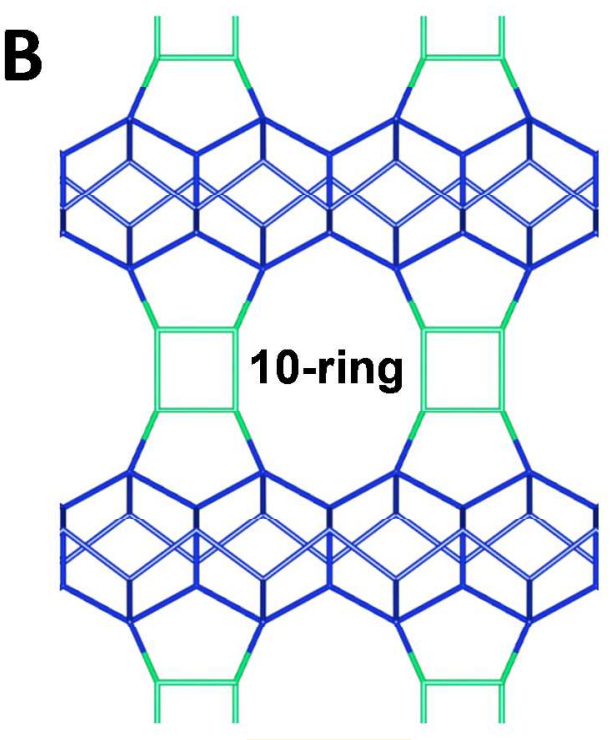

CIT-13

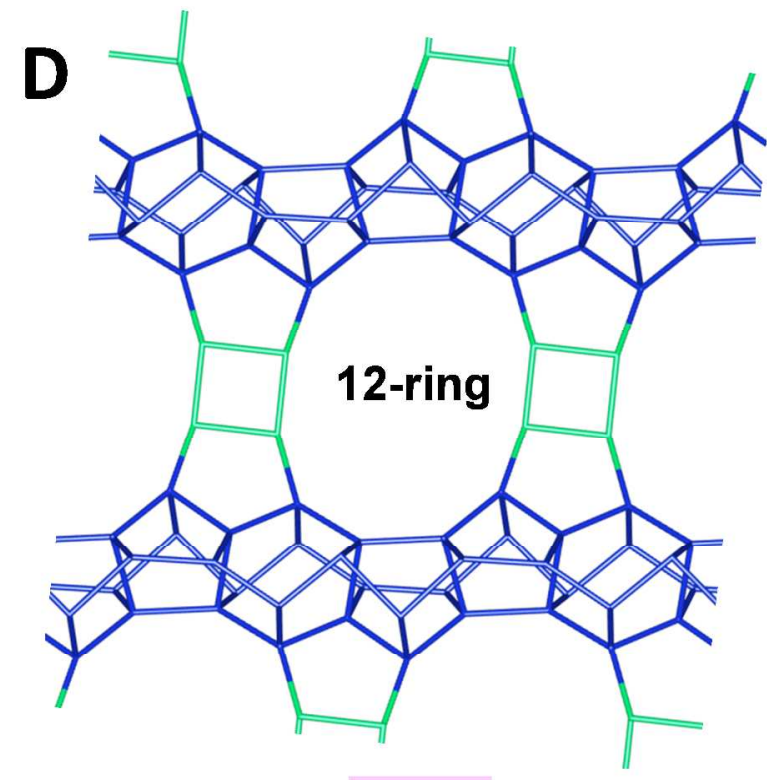

IM-12

Figure S1. Comparison between the crystal structures of CIT-13 and IM-12. (A) CIT-13 viewed along the [001] direction showing the 14-ring pore, and (B) along the [010 direction showing the 10-ring pore. (C) IM-12 viewed along the [001] direction showing the 14-ring pore, and (D) along the [010] direction showing the 12-ring pore. 


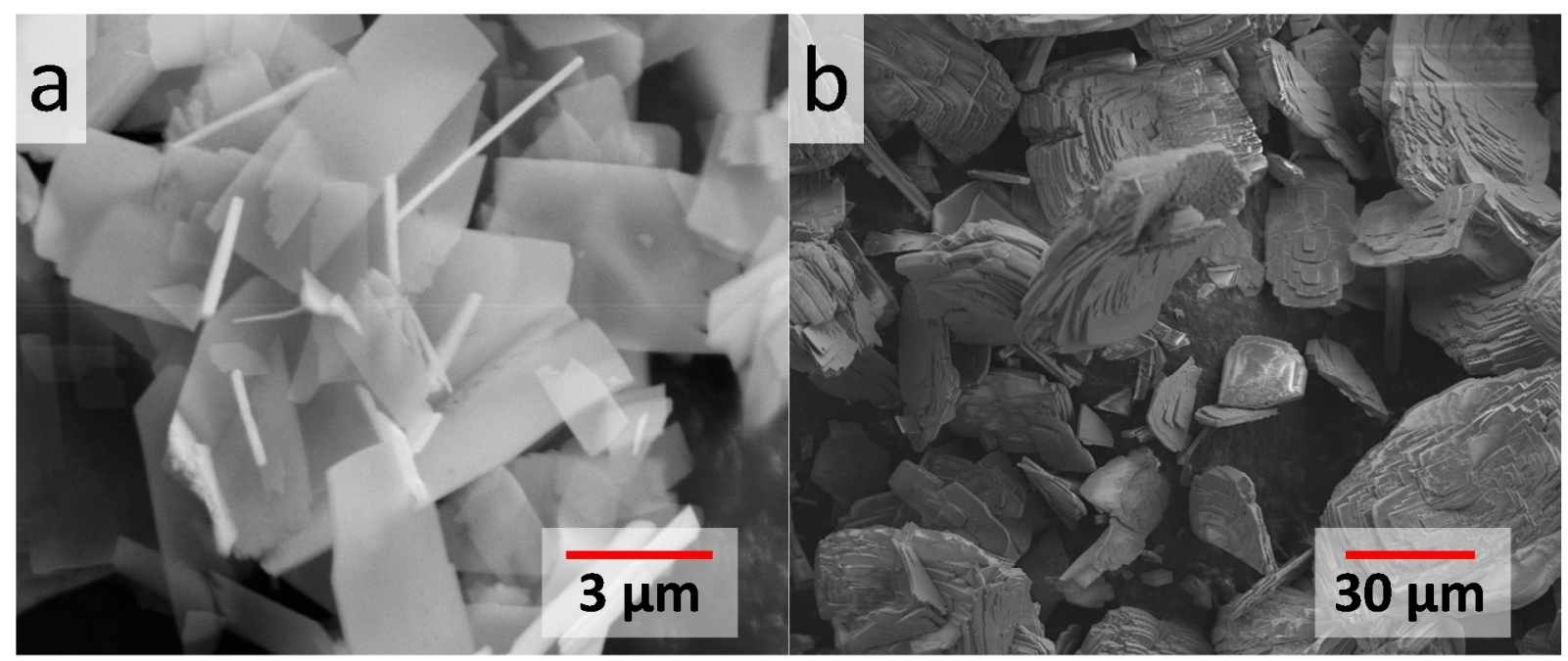

Figure S2. SEM micrographs of CIT-13 crystals prepared by heating $(A)$ in a rotating autoclave and (B) in a static autoclave. 

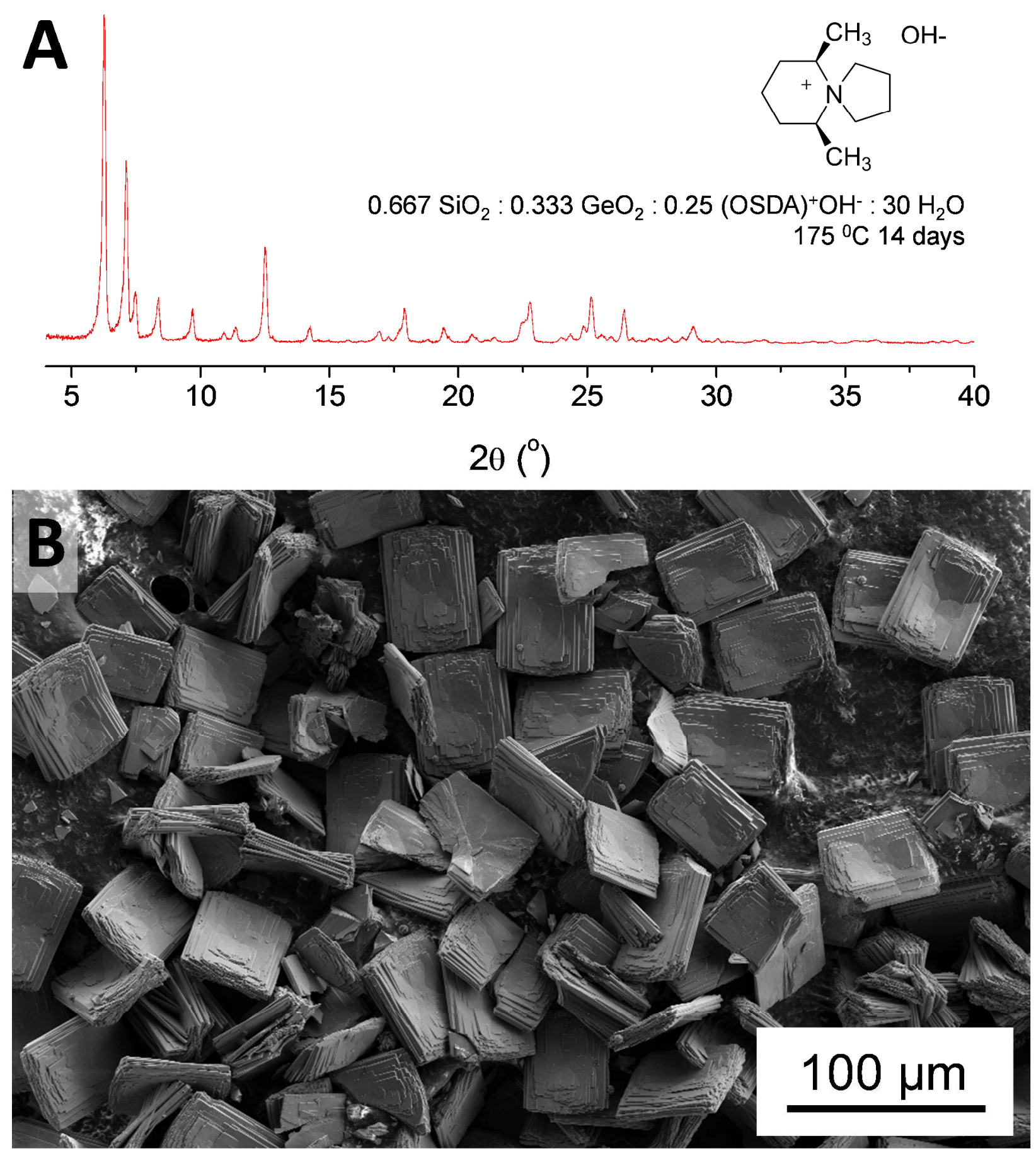

Figure S3. (A) An XPD pattern and (B) SEM image of a sample of the germanosilicate IM-12 synthesized in hydroxide medium (UTL framework type). The Si/Ge ratio was determined using EDS to be 4.5. This sample was used for comparison with CIT-13. 


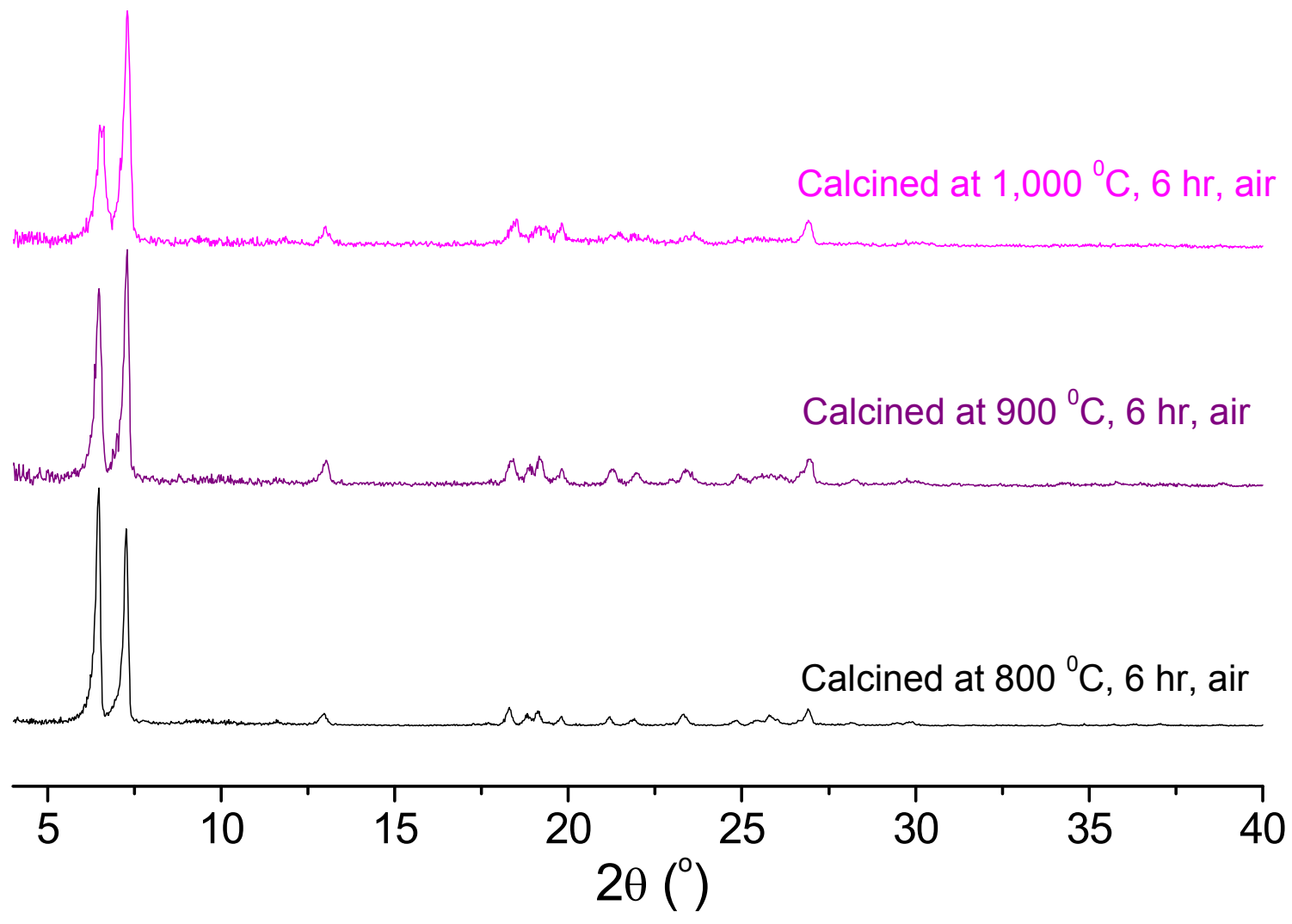

Figure S4. The XPD patterns of CIT-13 calcined in an air flow at high temperatures $\left(800{ }^{\circ} \mathrm{C}\right.$ to $1,000^{\circ} \mathrm{C}$ ) for 6 hours. 


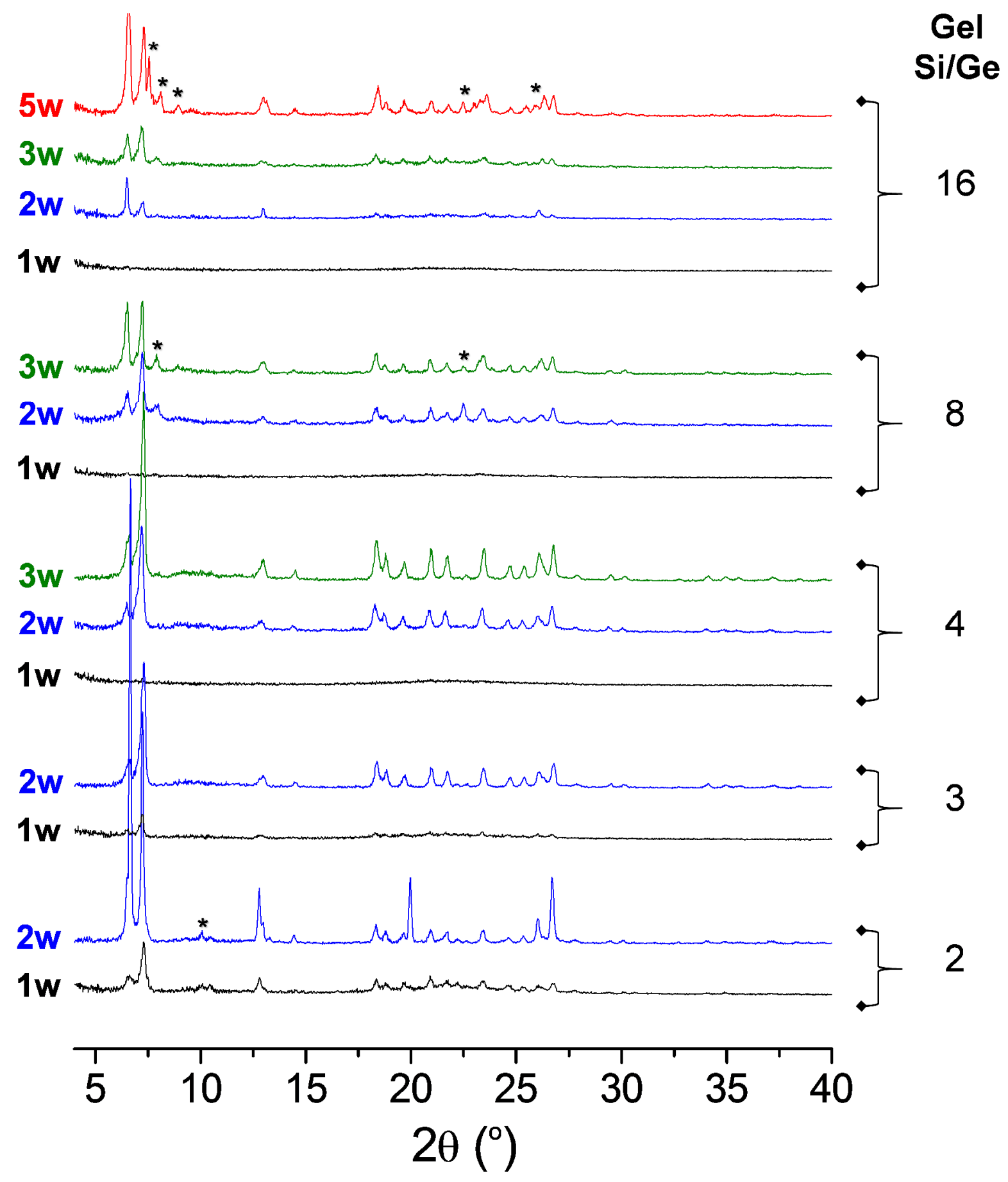

Figure S5. The effect of the Si/Ge ratio in the gel on the crystallization of CIT-13 (*: impurity; w: week). 


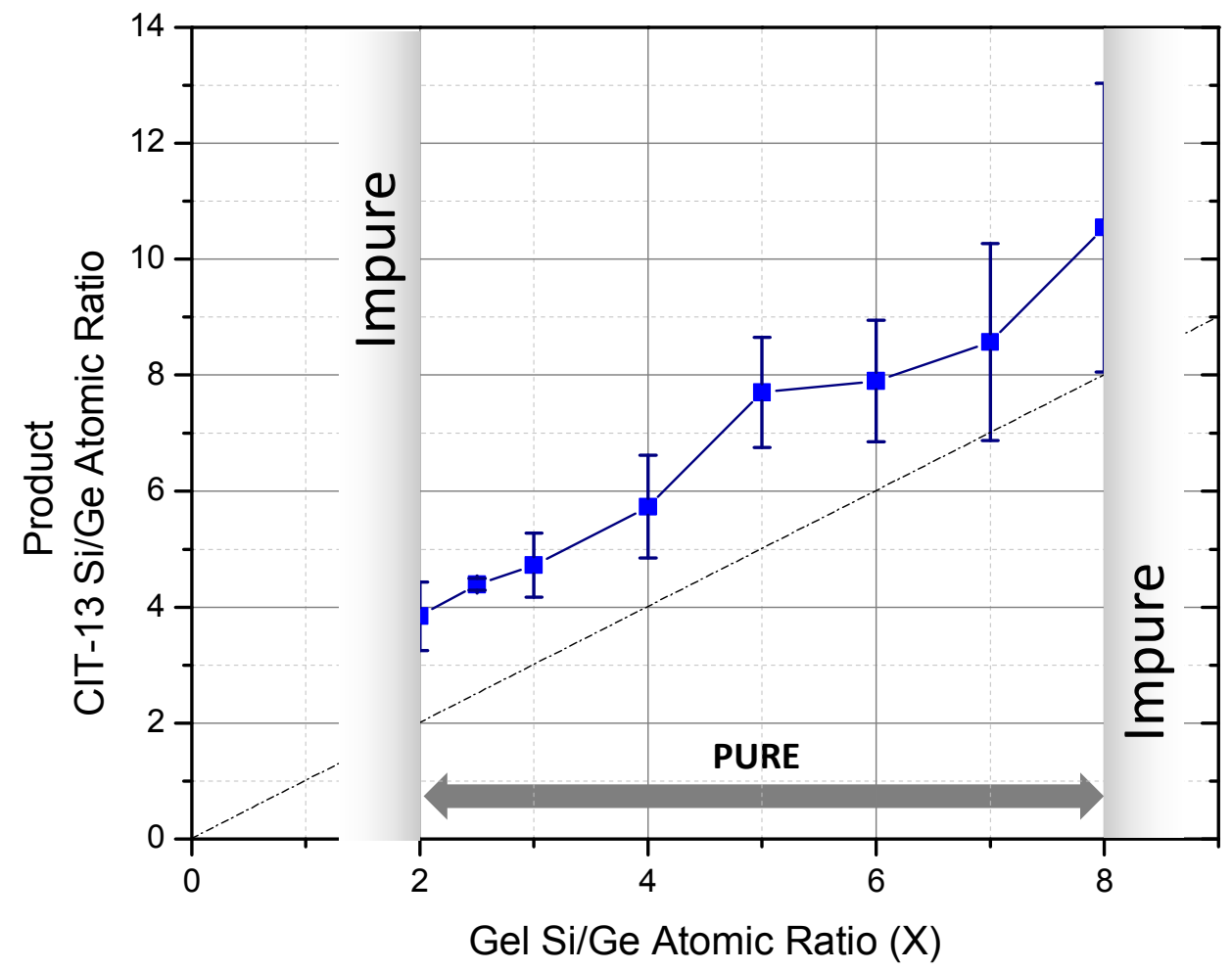

Figure S6. The relation between the gel $\mathrm{Si} / \mathrm{Ge}$ ratios and the product $\mathrm{CIT}-13 \mathrm{Si} / \mathrm{Ge}$ ratios, characterized using the EDS. 


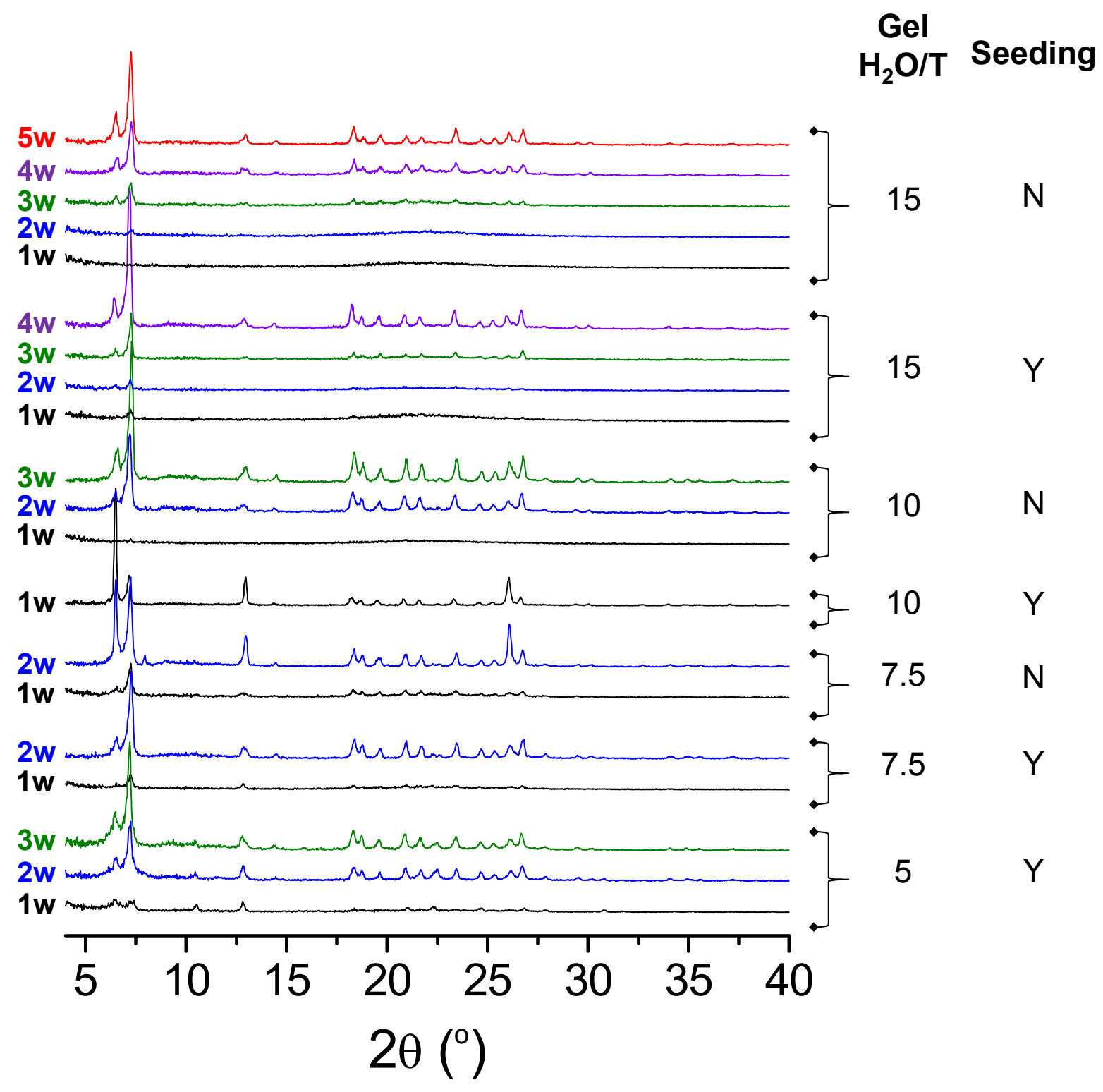

Figure S7. The effect of water levels in the gel on the crystallization of CIT-13 (w: week). 


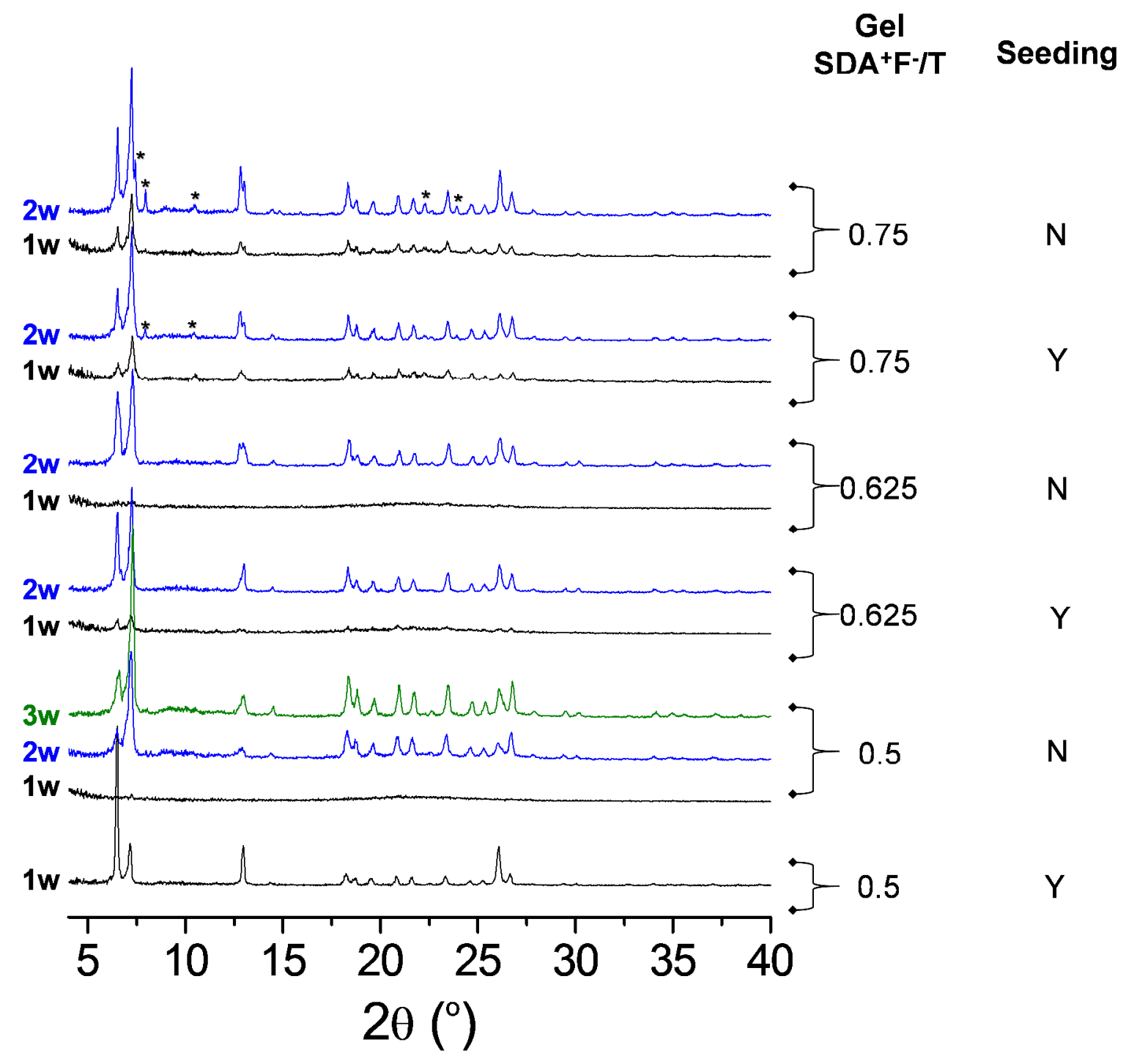

Figure S8. The effect of amount of OSDA in the gel on the crystallization of CIT-13 (*: impurity; w: week). 


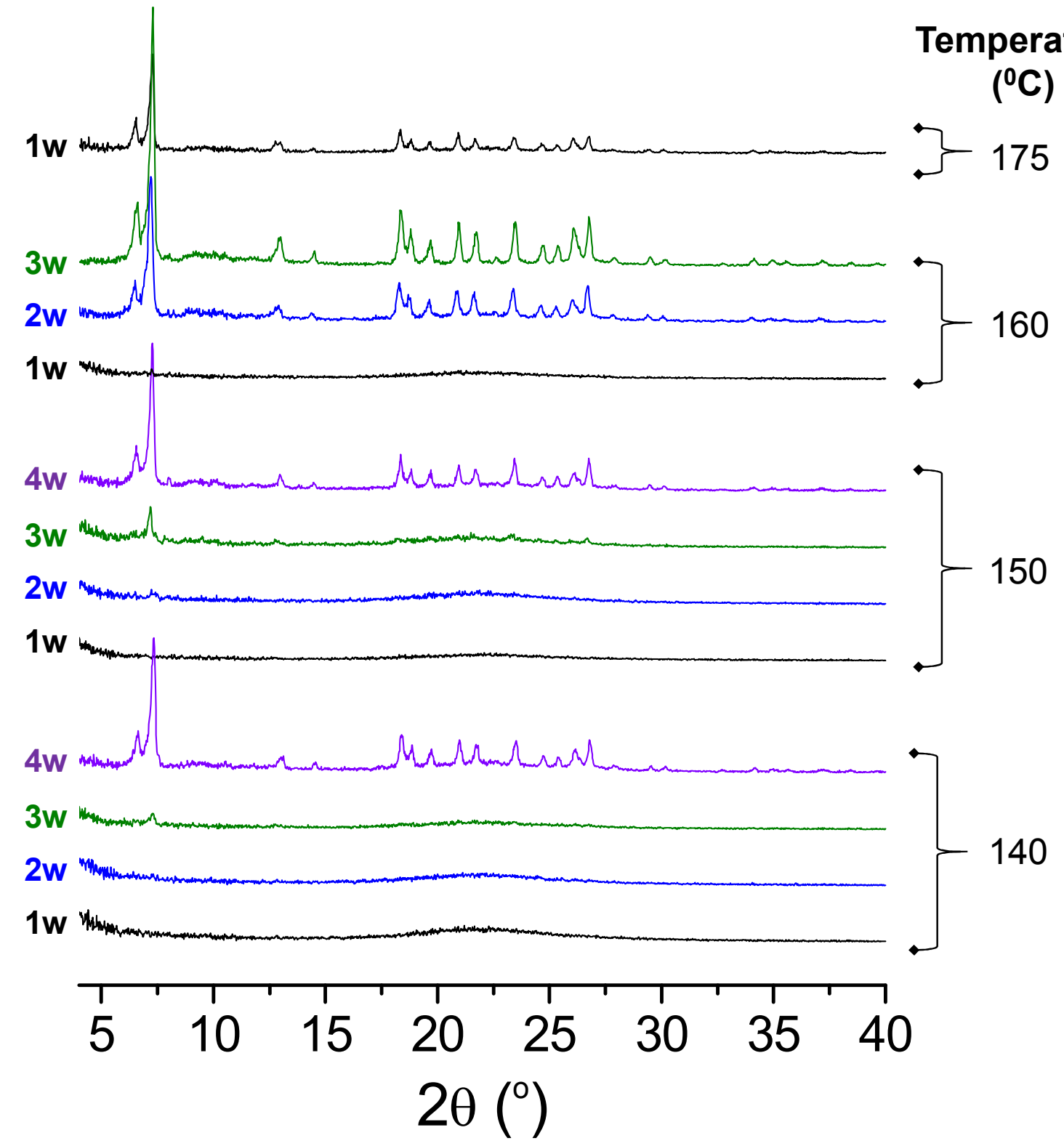

Figure S9. The effect of crystallization temperature on the crystallization of CIT-13 (*: impurity; w: week). 

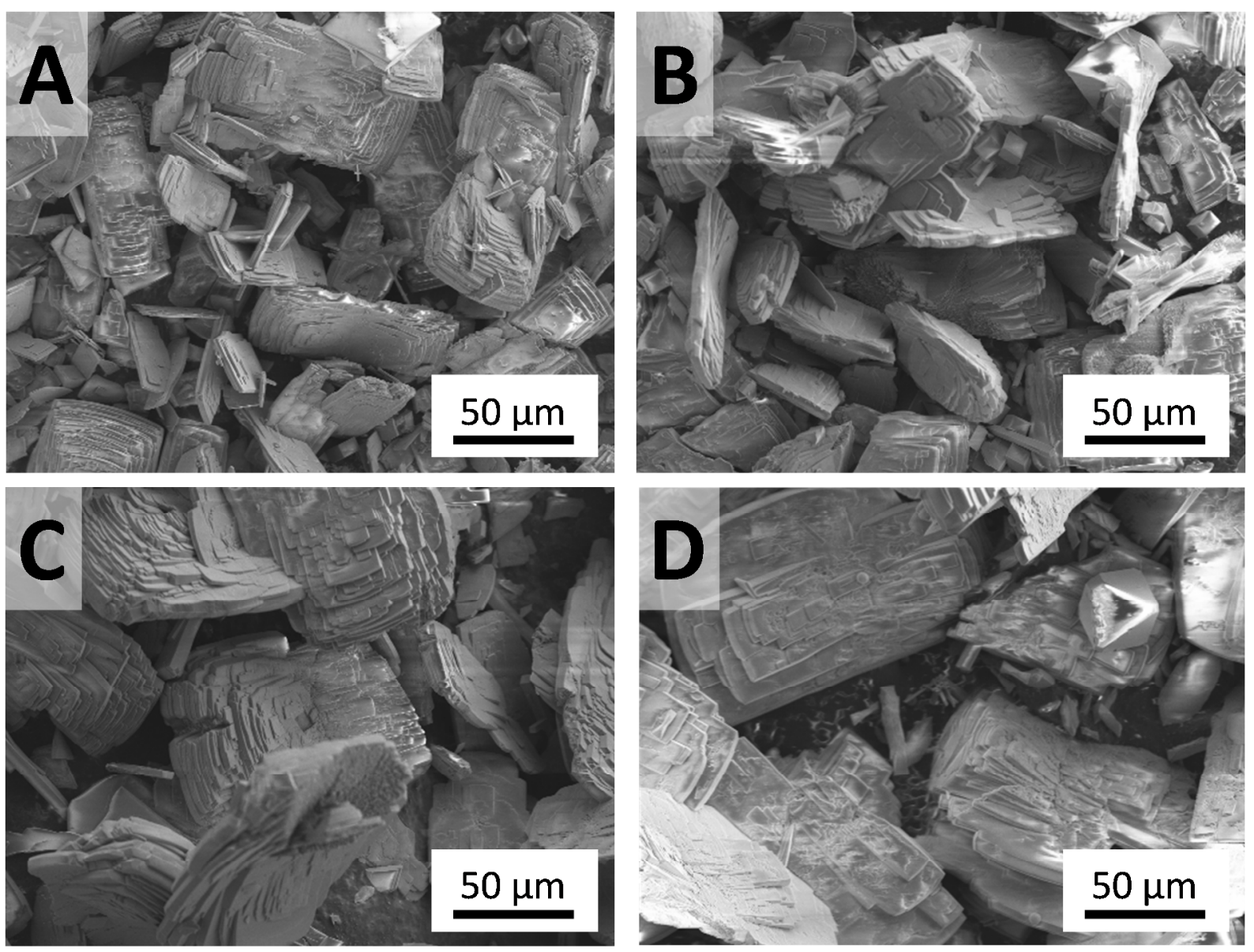

Figure S10. SEM micrographs of CIT-13 crystallized at (A) $140^{\circ} \mathrm{C},(\mathrm{B}) 150^{\circ} \mathrm{C}$, (C) $160^{\circ} \mathrm{C}$ and (D) $175^{\circ} \mathrm{C}$. 


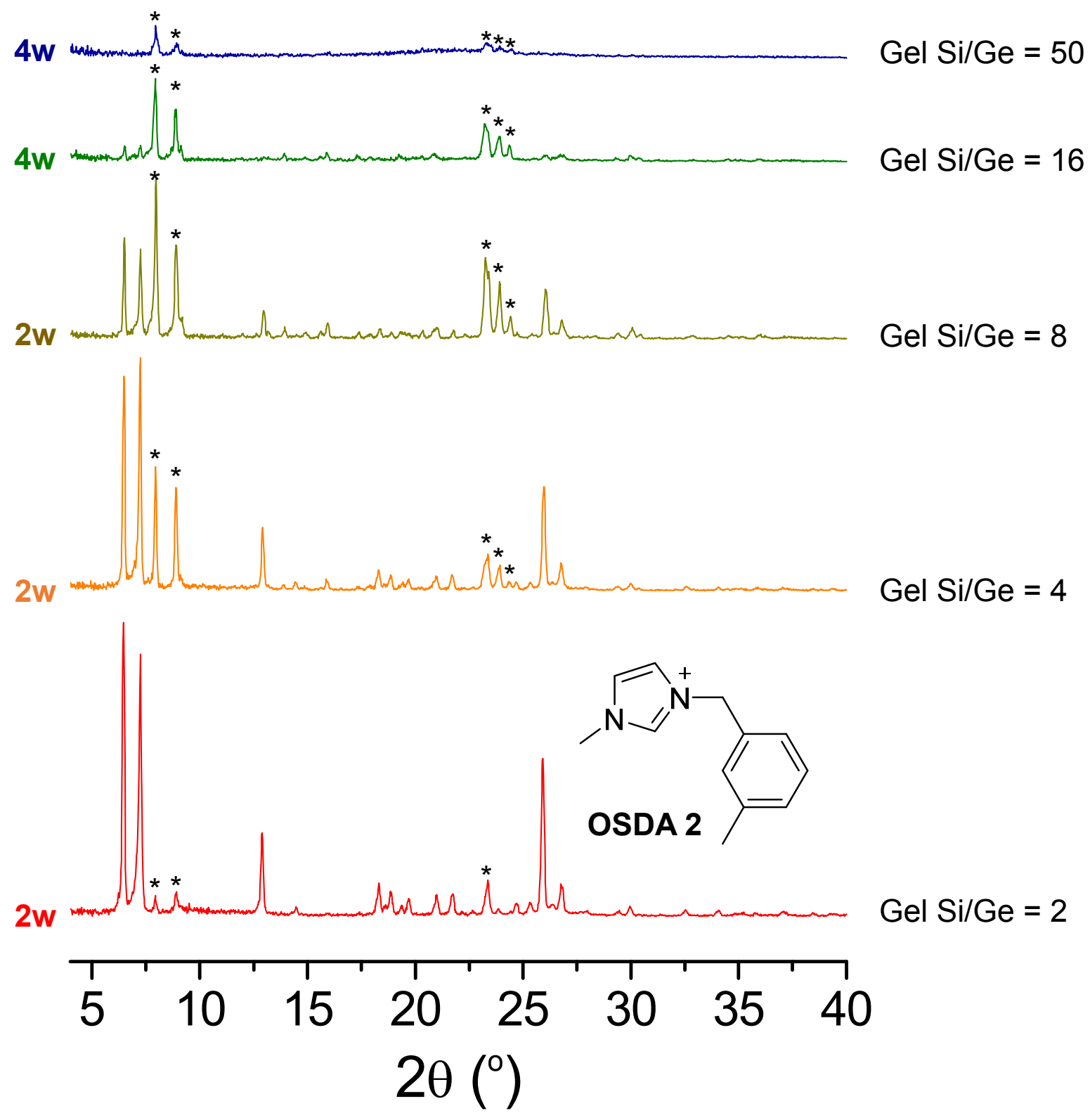

Figure S11. XPD patterns of germanosilicate samples that crystallized in the presence of OSDA 2 and different Si/Ge ratios and in the gel (*: impurity; w: week). Here, the impurity phase was identified as an MFI-type material. 

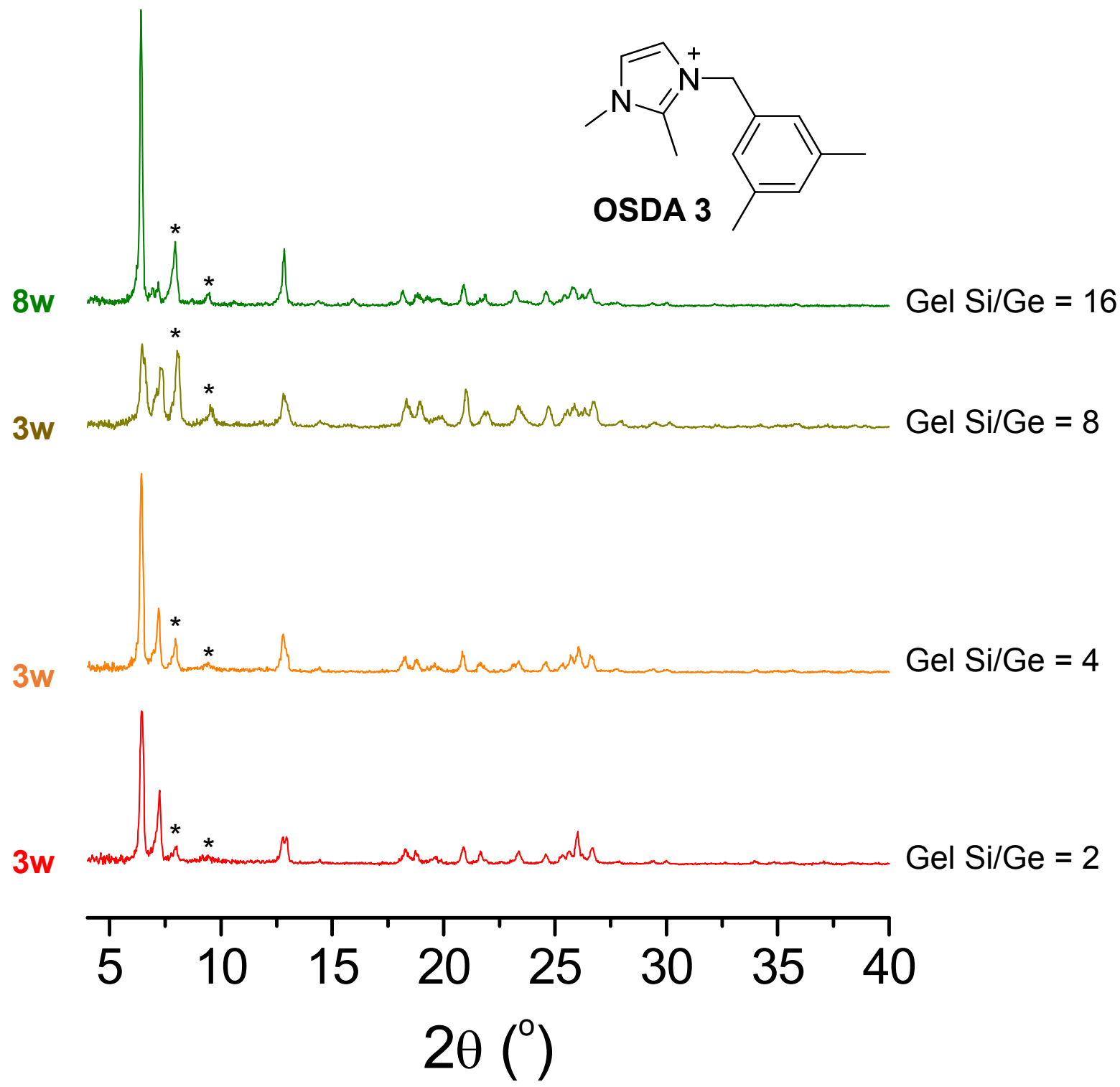

Figure S12. XPD patterns of germanosilicate samples that crystallized in the presence of OSDA 3 and different Si/Ge ratios and in the gel (*: impurity; w: week). 


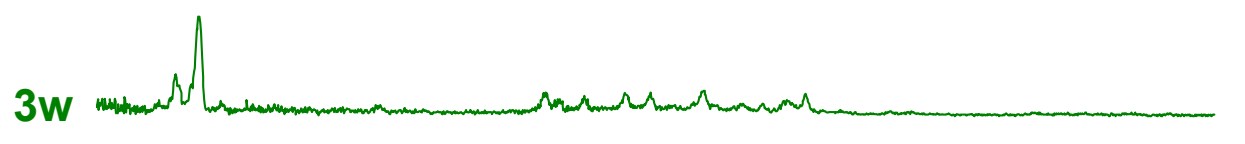

Gel Si $/ G e=16$

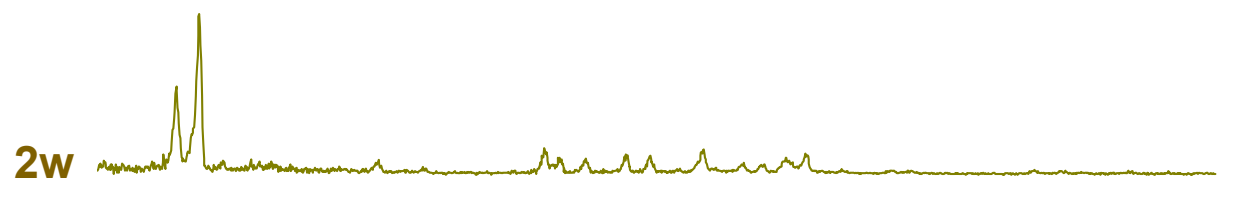

Gel Si $/ G e=8$

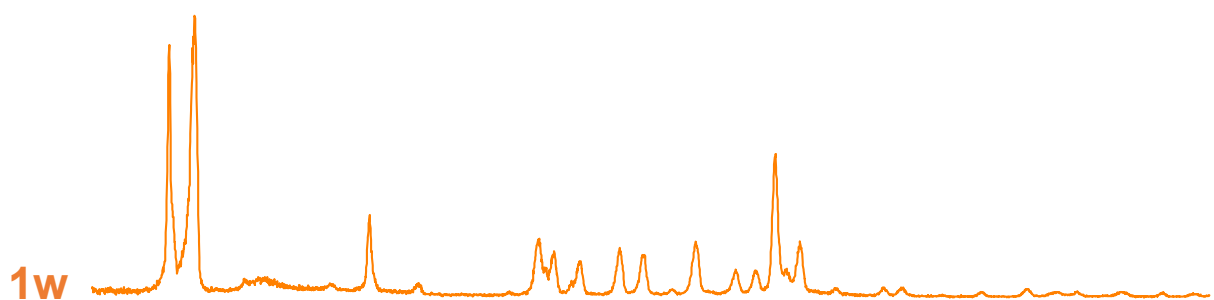

$\mathrm{Gel} \mathrm{Si} / \mathrm{Ge}=4$

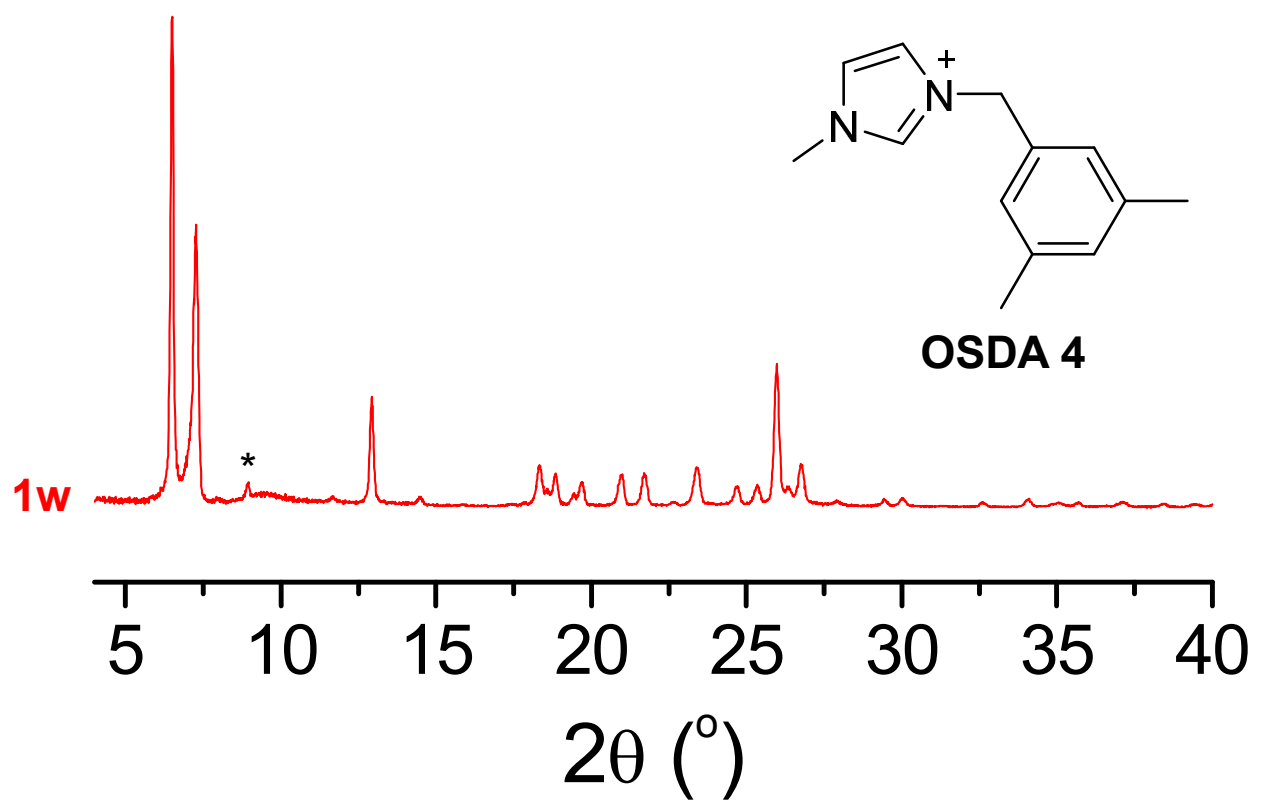

Figure S13. XPD patterns of germanosilicate samples that crystallized in the presence of OSDA 4 and different Si/Ge ratios and in the gel (*: impurity; w: week). 

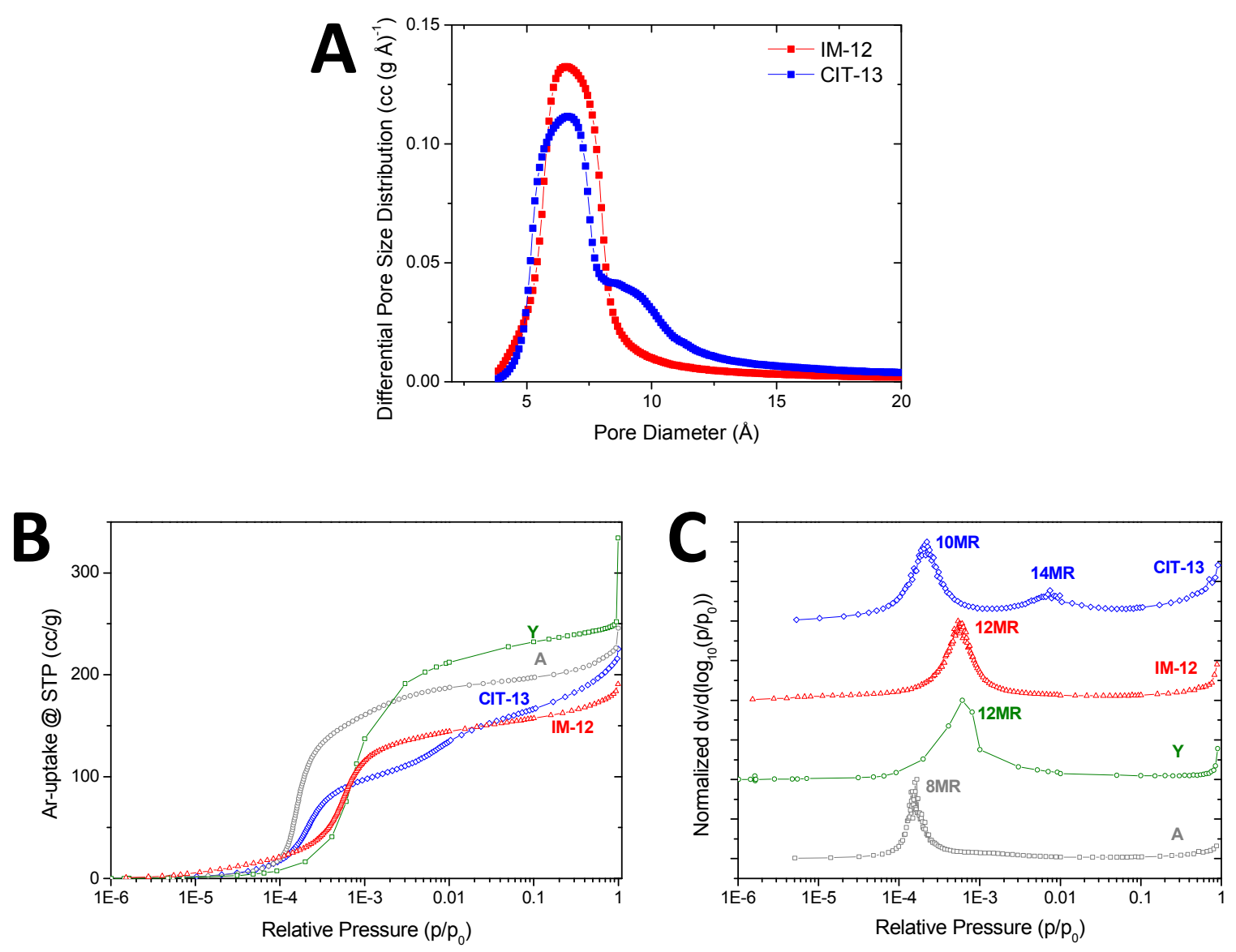

Figure S14. (A) The Saito-Foley pore size distribution derived from the argon adsorption isotherm shown in Figure 8. (B) The log-plot of the Ar-isotherms of CIT-13, IM-12, zeolite Y and zeolite A. (C) The normalized differentiated log-plot of isotherms in (B) to allow a qualitative comparison. Zeolite $Y$ and Zeolite A data courtesy of Dr. Joel E. Schmidt.

Since the small micropores are filled with argon atoms at a lower pressure then the large micropores, the position at which the inflection point in the log-plot is observed allows the pore size to be estimated qualitatively. For zeolite A (LTA) and zeolite $Y$ (FAU), the inflection points are observed at $\mathrm{p} / \mathrm{p}_{0}=10^{-3.80}$ and $10^{-3.22}$ (Figure S13B and $\mathrm{C}$ ), and these correspond to 8-rings and 12-rings, respectively. IM-12 (UTL) shows the inflection point at $p / p_{0}=10^{-3.26}$, which is very close to that of zeolite $\mathrm{Y}$, so this inflection point was assigned to 12 -rings in IM-12. CIT-13 was the only framework that showed two inflection points. The first was observed at $p / p_{0}=10^{-3.66}$ and assigned to the 10-rings and the second at $\mathrm{p} / \mathrm{p}_{0}=10^{-2.13}$ to the 14-rings. This second inflection point corresponding to 14-ring was not observable in IM-12. 
Table S1. Crystallographic details for the structure refinement of as-synthesized CIT-13.

\begin{tabular}{|c|c|}
\hline Sample & CIT-13 \\
\hline $\begin{array}{r}\text { Chemical } \\
\text { composition }\end{array}$ & $\left|\left(\mathrm{C}_{13} \mathrm{~N}_{2}\right)_{3.30} \mathrm{~F}_{2}\right|\left[\mathrm{Si}_{54.34} \mathrm{Ge}_{9.66} \mathrm{O}_{128}\right]$ \\
\hline Space group & $\mathrm{Cmmm}$ \\
\hline$a(\AA)$ & $27.4374(5)$ \\
\hline$b(\AA)$ & $13.8000(2)$ \\
\hline$c(\AA)$ & $10.2910(2)$ \\
\hline$V\left(\AA^{3}\right)$ & $3896.6(1)$ \\
\hline$Z$ & 8 \\
\hline$\rho\left(\mathrm{g} / \mathrm{cm}^{3}\right)$ & $2.144(2)$ \\
\hline$\lambda(\AA)$ & 0. 776381(1) \\
\hline $2 \theta$ range $\left({ }^{\circ}\right)$ & $2.0-46.0$ \\
\hline$R_{1}$ & 0.0126 \\
\hline$R_{\mathrm{wp}}$ & 0.0773 \\
\hline$R_{\exp }$ & 0.0015 \\
\hline Observations & 16899 \\
\hline Reflections & 1241 \\
\hline Parameters & 104 \\
\hline Geometric & 62 (zeolite) \\
\hline restraints & 38 (SDA) \\
\hline
\end{tabular}

Table S2. Selected bond lengths and angles $\left(\AA{ }^{\circ}{ }^{\circ}\right)$.

\begin{tabular}{llccc}
\hline & & T-O-T & O-T-O & T-0 \\
\hline CIT-13 & $\min$ & 138.3 & 107.8 & 1.55 \\
& $\max$ & 180.0 & 113.8 & 1.63 \\
& avg & 156.6 & 109.6 & 1.59 \\
\hline
\end{tabular}

Restraints used: T-O-T: $135 \pm 10^{\circ} ; \mathrm{O}-\mathrm{T}-\mathrm{O}: 109.5 \pm 0.8^{\circ} ; \mathrm{T}-\mathrm{O}: 1.61 \pm 0.01 \AA \mathrm{A} ; w=1 / \sigma^{2}$ 